\title{
Expression of RIG-I, IRF3, IFN-ß and IRF7 determines resistance or susceptibility of cells to infection by Newcastle Disease Virus
}

\author{
HOLGER WILDEN $^{1}$, PHILIPPE FOURNIER ${ }^{1}$, RAINER ZAWATZKY $^{2}$ and VOLKER SCHIRRMACHER ${ }^{1}$ \\ ${ }^{1}$ Division of Cellular Immunology, German Cancer Research Center, Im Neuenheimer Feld 280; \\ ${ }^{2}$ Division of Viral Transformation Mechanisms, German Cancer Research Center, \\ Im Neuenheimer Feld 242, D-69120 Heidelberg, Germany
}

Received July 4, 2008; Accepted September 10, 2008

DOI: 10.3892/ijo_00000223

\begin{abstract}
Newcastle Disease Virus (NDV) is an avian paramyxovirus with anti-neoplastic and immune-stimulatory properties which has raised considerable interest for cancer therapy. To better understand the molecular nature of the tumor selective replication of NDV, we investigated the cellular responses of murine normal and tumor cells after infection by NDV. To this end, we compared the basal expression of different antiviral proteins as well as the expression induced by the addition of NDV to the cells in vitro and in vivo. Primary macrophages were found to be resistant to NDV infection and exhibited a high basal and induced expression of various antiviral genes. In contrast, macrophagederived RAW tumor cells were highly susceptible to NDV infection and displayed a low expression of several antiviral genes. Macrophage-derived J774 tumor cells were intermediate with regard to NDV replication and antiviral gene expression. The responsiveness to exogenously added IFN- $\alpha$ was found highest in normal macrophages, lowest in the RAW cells, and intermediate in the $\mathrm{J} 774$ cells. We also analysed dendritic cells as well as additional normal and tumor cell types. A strong inverse correlation was obeserved between the susceptibility to infection and the basal expression of the antiviral genes RIG-I, IRF3, IRF7 and IFN-B. A strong expression of these genes can explain the resistance of normal cells to NDV infection and a weak antiviral gene expression the broad susceptibility of tumor cells.
\end{abstract}

\section{Introduction}

The systemic application of oncolytic NDV strains in cancer patients has been described to be well tolerated (1). Patient

Correspondence to: Professor V. Schirrmacher, Division of Cellular Immunology (D010), German Cancer Research Center (DKFZ), Im Neuenheimer Feld 280, D-69120 Heidelberg, Germany

E-mail: v.schirrmacher@dkfz.de

Key words: interferon, tumor selectivity, cellular response, paramyxovirus, macrophage responses to therapy with NDV have been described for glioblastoma multiforme $(2,3)$ and other tumors (4-6). One reason for the good tolerability appears to be that normal cells react to and resist NDV infection. NDV has been shown to have immune stimulatory properties so that it is being used as an adjuvant of a tumor vaccine. Application of vaccines based on autologous tumor cells infected with NDV seemed to improve long-term survival of patients with different cancer types beyond what is seen after conventional standard therapies (7-9). Recently such an approach has been shown to be successful in a randomised prospective phase III study in colon carcinoma (10). Another important feature of NDV is its tumor selective replication. NDV was reported to replicate up to 10,000 times better in tumor than in normal cells (11).

To better understand the functions of NDV it is important to elucidate at the molecular level the basis for its selective replication in tumor cells. This feature cannot be attributed to its binding properties since NDV binds to and infects cells via interaction with ubiquitious sialic acid-containing cell surface molecules (glycoproteins and glycolipids). These receptors are expressed on tumor as well as normal cells. However, following infection of normal mammalian cells, antiviral immune responses are initiated by the secretion of type I interferons (IFNs) such as IFN- $\alpha$ and IFN- $\beta$. This feature is important in the case of the use of NDV since this virus is known as a strong inducer of such IFNs in mammalian cells, especially when added to human peripheral blood cells $(12,13)$. The IFN response has been shown to be selectively inhibited by the viral $\mathrm{V}$ protein in cells derived from the normal host of replication of NDV (14). However, no escape mechanism to the IFN response has been described in mammalian cells. Following NDV entry into a cell and the onset of virus replication, single- and double-stranded viral RNA is generated in the cytoplasm. Such viral RNA constitutes a pathogen-associated molecular pattern that is detected in the cytosol by RIG-I, an RNA helicase $(15,16)$. The structural basis for the distinction of viral RNA from abundant self RNA seems to be 5'-triphosphate RNA generated by viral polymerases $(17,18)$. Detection of viral RNA by RIG-I leads to the phosphorylation of the transcription factor interferon regulatory factor 3 (IRF3) that translocates to the nucleus and induces the transcription of IFN- $\beta$ and some IFN- $\alpha$ subtypes. These IFNs bind to the IFN- $\alpha / \beta$ receptor (19) and induce a second phase feedback loop of increased IFN production. 
The second loop of the response involves activated Janus kinases and STAT transcription factors which induce many genes with antiviral function. Among the induced genes is IRF7 which, unlike IRF3, is either absent or present only at low levels in most cell types apart from plasmacytoid dendritic cells (20). IRF7 is also activated by RIG-I and further induces the transcription of IFN- $\beta$ and IFN- $\alpha$ (21). This IFN-based positive feedback induction of IRF7 is crucial for a strong IFN response (22). In addition to IRF7, proteins with direct antiviral functions such as the protein kinase R (PKR), the 2'-5'-oligoadenylate synthetase (OAS) or myxovirus resistance protein $(\mathrm{Mx})$ are induced. These proteins increase cellular resistance to virus infection and limit viral spread from cell to cell.

To define the mechanism explaining the selective replication of NDV in tumors, we studied in vitro and in vivo the susceptibility of macrophages and macrophage-derived tumor cells to NDV infection. We compared this with the IFN response induced in these cells after addition of NDV. For this purpose, we examined the constitutive and NDV-induced expression of antiviral IFN-related genes. We also analysed the secretion of type I IFNs by the cells and their responsiveness to IFNs. This study shows the existence of a strong correlation between replication of NDV and the level of expression of the four genes RIG-I, IRF3, IRF7 and IFN-B.

\section{Materials and methods}

Tumor cell lines. The murine macrophage-derived cell lines J774A.1 (here named J774) and RAW 264.7 (here named RAW) and the Eb/ESb lymphoma lines were obtained from the tumor bank at the German Cancer Research Center (Heidelberg, Germany). The CT26w colon carcinoma cell line was obtained from I.J. Fidler (Department of Cancer Biology, The University of Texas M.D. Anderson Cancer Center, Houston, TX, USA). The B16-F10 melanoma and 3LL Lewis lung carcinoma cell lines were obtained from the ATCC, Rockville, MD, USA. DA3 mouse mammary adenocarcinoma cells were kindly provided by G. Moldenhauer and MB-49 mouse bladder carcinoma cells by G. Hämmerling (both Division of Molecular Immunology, German Cancer Research Center). Cells were grown in DMEM (MB-49, J774, RAW, DA3, CT26) or RPMI-1640 medium (all other tumor cell types) supplemented with $1 \%$ heat-inactivated FCS, $100 \mathrm{U} / \mathrm{ml}$ penicillin and $100 \mu \mathrm{g} / \mathrm{ml}$ streptomycin (all reagents purchased from Gibco Invitrogen, Karlsruhe, Germany). The growth medium of the DA3 and ESb 289 cells was additionally supplemented with $B$-mercaptoethanol to a final concentration of $0.05 \mathrm{mM}$. All cells were propagated at $37^{\circ} \mathrm{C}$ in a humidified atmosphere containing $5 \% \mathrm{CO}_{2}$.

Normal, non-malignant cells. Murine macrophages were generated by growing bone marrow cells flushed from femora in RPMI-1640 medium supplemented with 10\% heat-inactivated FCS, antibiotics and 20\% murine M-CSF-containing supernatant from L929 cells. After 10 days, the adherent cells were recovered from the cell culture plates and the macrophage phenotype determined by flow cytometry after staining with a monoclonal anti-F4/80 antibody. Expression of the F4/80 macrophage marker was found in $>80-90 \%$ of the cells.
Dendritic cells were generated by culturing bone marrow cells in RPMI-1640 medium supplemented with $10 \%$ heatinactivated FCS, antibiotics and 15\% murine GM-CSFcontaining supernatant from Ag8.653 myeloma cells (kindly provided by B. Kyewski (Division of Developmental Immunology, German Cancer Research Center). Fresh medium was added on day 3, 6 and 8, and on day 9 LPS (Sigma-Aldrich, Schnelldorf, Germany) was added to a final concentration of $1 \mu \mathrm{g} / \mathrm{ml}$ to induce maturation. On day 10 the cells were harvested. Expression of CD11c dendritic cell marker was $>70 \%$. Spleen cells were prepared from murine spleen and cultivated in RPMI-1640 medium supplemented with $10 \%$ heat-inactivated FCS. All cells were cultured at $37^{\circ} \mathrm{C}$ in a humidified atmosphere containing $5 \% \mathrm{CO}_{2}$.

Mice. BALB/c, C57BL/6, DBA/2 and non-obese diabetic/ severe combined immunodeficient (NOD/SCID) mice were purchased from Charles River Laboratories (Sulzfeld Germany).

Viruses. Recombinant NDV expressing EGFP (NDFL-EGFP) was generated from a cDNA clone of the lentogenic NDV strain La Sota as described (23). Lentogenic NDV Ulster 2C was obtained in 1984 from P.H. Russel (University London, UK) and velogenic NDV Italien in 1986 from H.D. Klenk (University of Giessen, Germany). All viruses were propagated in embryonated chicken eggs, harvested from the allantoic fluid, purified by ultracentrifugation as described (24) and cryopreserved in aliquots at $-70^{\circ} \mathrm{C}$. The virus was quantified by a hemagglutination assay. One hemagglutination unit (HU) is defined as the smallest virus concentration leading to visible sheep erythrocyte agglutination.

Virus infections. Cell suspensions were washed twice with FCS-free medium and $1 \times 10^{6}$ cells were incubated with $10 \mathrm{HU}$ of NDV in a final volume of $100 \mu \mathrm{l}$ for $1 \mathrm{~h}$ at $37^{\circ} \mathrm{C}$ in a cell culture incubator. During the incubation, cells were shaken every $15 \mathrm{~min}$. The cells were then washed twice and cultured further in $2 \mathrm{ml}$ medium with $10 \%$ FCS in a 12-well plate. To generate UV-inactivated NDV, the virus suspension was exposed to UV light for $5 \mathrm{~min}\left(254 \mathrm{~nm}, 2 \mathrm{~mW} / \mathrm{cm}^{2}, 7 \mathrm{~cm}\right.$ distance).

Antibodies and sera. Polyclonal rabbit anti-NDV serum was prepared by immunizing rabbits four times subcutaneously with $40,000 \mathrm{HU} / \mathrm{ml}$ of NDV Ulster mixed 1:1 with incomplete Freund's adjuvant. Pre-immune serum and the antiserum were heat-inactivated (for $45 \mathrm{~min}$ at $56^{\circ} \mathrm{C}$ ), aliquoted and stored at $-20^{\circ} \mathrm{C}$. Monoclonal antibodies were obtained from the following providers: chicken anti-rabbit-FITC (Invitrogen), anti-F4/80-PE (Cedarlane Labs, Burlington, Ontario, Canada), CD11c-FITC (BD Pharmingen, Heidelberg, Germany). Mouse rIFN- $\alpha 4$ was obtained from the culture medium of Chinese hamster ovary $(\mathrm{CHO})$ cells transfected with an expression vector harboring mouse IFN- $\alpha 4$ cDNA as described previously (25).

Flow cytometry. $4 \times 10^{5}$ cells per sample were used for analysis by a FACScan flow cytometer (Becton-Dickinson, Heidelberg, Germany). All antibodies were diluted in FACS buffer (PBS 
containing 5\% FCS and $0.1 \% \mathrm{NaN}_{3}$ ). Antibody incubations were performed for $20 \mathrm{~min}$ on ice in the dark. Cells were washed twice with FACS-buffer between each antibody incubation. All FACS data were analyzed with the WinMDI 2.8 software (Joe Trotter, The Scripps Research Institute, CA, USA).

RNA isolation and preparation of cDNA. Cells were washed in PBS and cell pellets were either shock-frozen in liquid nitrogen for storage at $-80^{\circ} \mathrm{C}$ or immediately used for RNA isolation. Cells were disrupted using a rotor-stator homogeniser. Total RNA was extracted using the RNeasy mini kit (Qiagen, Hilden, Germany) according to the manufacturer's instructions. Five hundreds nanograms of the total RNA was then reversely transcribed into cDNA using Oligo $(\mathrm{dT})_{12-18}$ primers and the SuperScript ${ }^{\mathrm{TM}}$ II Reverse Transcriptase (both Invitrogen) according to the manufacturer's instructions.

Quantitative real-time PCR ( $q P C R)$. Quantitative PCR was carried out using a Gene Amp ${ }^{\mathrm{TM}} 5700$ Sequence Detection System (Applied Biosystems GmbH, Weiterstadt, Germany). After an initial incubation of $25 \mu 1$ reaction mix (Eurogentec, Seraing, Belgium) for $10 \mathrm{~min}$ at $95^{\circ} \mathrm{C}$, amplification was performed for 45 cycles consisting of a 15 -sec hold at $95^{\circ} \mathrm{C}$ and a 1-min hold at $60^{\circ} \mathrm{C}$. The expression of the target genes was normalised with the respective housekeeping gene after it had been ensured that the amplification efficiency was the same. To determine NDV M gene expression, a FAM-TAMRA probe system (5'-6-Carboxy-fluorescein + 3'-6-Carboxy-tetramethylrhodamine) was used and normalisation was carried out with $3-$ actin. The expression of the cellular genes was analysed with a SYBR green system and normalisation was done with the acidic ribosomal phospho-protein PO (Arbp).

The oligonucleotide sequences used for the probe system were as follows: NDV M (matrix) gene 5'-AGT GAT GTG CTC GGA CCT TC-3', 5'-CCT GAG GAG AGG CAT TTG CTA-3' and 5'-TTC TCT AGC AGT GGG ACA GCC TGC-3' (FAM-TAMRA probe), B-Actin 5'-ACG GCC AGG TCA TCA CTA TTG-3', 5'-AGG ATT CCA TAC CCA AGA AGG AA-3' and 5'-CAA CGA GCG GTT CCG ATG CCC-3' (FAM-TAMRA probe). The oligonucleotides used for the SYBR green system had the following sequences: RIG-I 5'-CCC AAC CGA TAT CAT TTC TGA-3' and 5'-AGT TTT GGG CCA GTT TTC CT-3', MDA5 5'-TGT CTT GGA CAC TTG CTT CG-3' and 5'-CTG CAC AAT CCT TCT CAG CA-3', IRF3 5'-GTG CCT CTC CTG ACA CCA AT-3' and 5'-CCA AGA TCA GGC CAT CAA AT-3', IRF7 5'AAG CTG GAG CCA TGG GTA TG-3' and 5'-GAC CCA GGT CCA TGA GGA AG-3', IFN- 3 5'-AGC TCC AAG AAA GGA CGA ACA T-3' and 5'-GCC CTG TAG GTG AGG TTG ATC T-3', PKR 5'-GTT AAA GAG CCC GCC GAA A-3' and 5'-CTG CTG GAA AAG CCA CTG AAT-3', OAS1a 5'-CTT AGC ATG GAG CAC GGA CT-3' and 5'-TTT GAC ATC AGC ACC AAA GG-3', Mx1 5'-AAA CCT GAT CCG ACT TCA CTT CC-3' and 5'-TGA TCG TCT TCA AGG TTT CCT TGT-3', Arbp 5'-CGA CCT GGA AGT CCA ACT AC-3' and 5'-ATC TGC TGC ATC TGC TTG-3'.

IFN- $\alpha$ and IFN- $\beta$ enzyme-linked immunosorbent assay (ELISA). Type I interferons in supernatants of cultured cells were determined with ELISA using rat monoclonal antibody against murine IFN- $\alpha$ and rabbit polyclonal antibody against murine IFN- $\alpha$ and IFN- $\beta$ (PBL Interferon Source, NJ, USA). Rat monoclonal antibody against murine IFN- $\beta$ was purchased from United States Biological (MA, USA). Peroxidaseconjugated AffiniPure $\mathrm{F}\left(\mathrm{ab}^{\prime}\right)_{2}$ fragment donkey anti-rabbit IgG $(\mathrm{H}+\mathrm{L})$ was obtained from Jackson ImmunoResearch Laboratories, PA, USA.

Encephalomyocarditis virus (EMCV) protection assays. This virus protection assay was performed as described (25) using EMCV virus and L929 indicator cells. The dilution of a supernatant that protected $50 \%$ of the cells against virusinduced lysis contained by definition one international unit (IU) IFN.

In vivo chamber experiments. The micro-chambers were constructed as described (26). They consisted of a plastic ring with a rubber cap on one side and a polycarbonate membrane with $3 \mu \mathrm{m}$ pore size on the other side. The volume of the chambers was $\sim 80 \mu 1$. Uninfected or NDV-infected cells $\left(5 \times 10^{5}\right)$ suspended in normal growth medium were injected into the chambers via the rubber cap using a syringe with a 0.4-mm diameter needle. Immediately after injection of the cells the chambers ( 2 per mouse) were implanted subcutaneously into the flank of anesthetized NOD/SCID mice. After $24 \mathrm{~h}$ the chambers were recovered and the rubber cap removed. The liquid inside the chambers was removed for the analysis of secreted IFNs. To lyse the remaining cells, lysis buffer was given into the chambers for cell lysis. Extraction of RNA and subsequent analysis was then performed as described above.

Statistical analyses. All analyses were done with the GraphPad Prism 4.0 software (GraphPad Software, Inc., San Diego, CA, USA). P-values were calculated with a two-sided Student's t-test. Correlation analyses were performed using the Spearman's correlation coefficient.

\section{Results}

Higher resistance of normal cells to NDV infection compared to tumor cells. A variety of murine tumor cells and normal cells such as macrophages, lymphocytes and dendritic cells were infected with NDV. One day later, we measured the amount of the viral $\mathrm{M}$ gene by quantitative RT-PCR. As shown in Fig. 1A, viral $\mathrm{M}$ gene expression was on average $\sim 1000$ times higher in tumor cells compared to normal cell types.

In order to define molecular differences between normal and tumor cells explaining such a difference, we compared bone marrow-derived macrophages and the two macrophagederived tumor cell lines $\mathbf{J} 774$ and RAW after infection with NDV Ulster. Viral gene expression was determined at different time-points post infection either at the cell surface by flow cytometry (Fig. 1B) or in the cytoplasm by quantitative RT-PCR (qRT-PCR) (Fig. 1C). Viral M gene expression remained at a low level in primary macrophages, whereas, in the RAW tumor cell line, it increased 500-fold. Twenty-four hours after infection, $93 \%$ of the RAW cells were found 
A

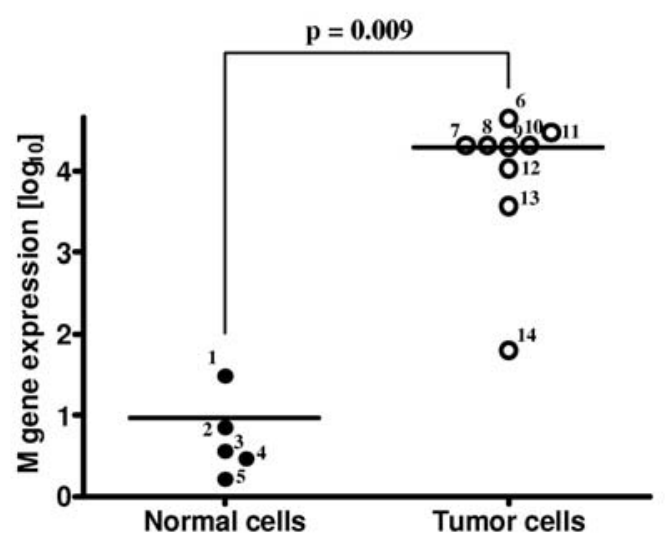

B

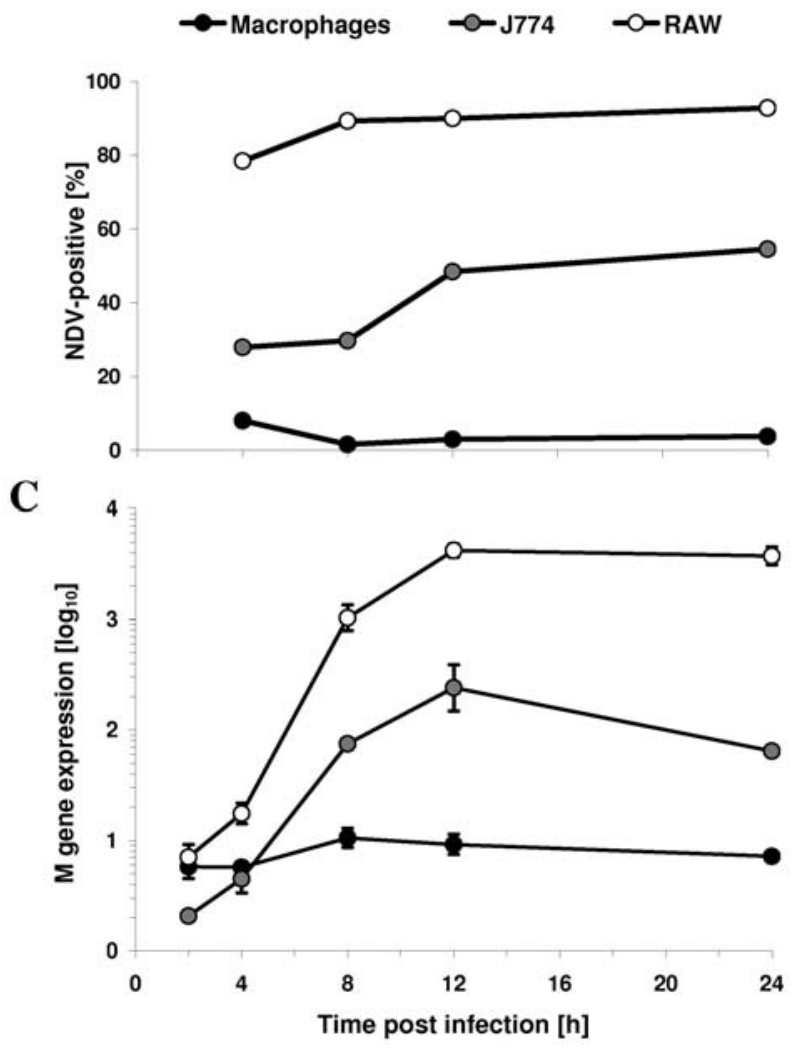

Figure 1. Replication of NDV in normal and tumor cells. (A) Different normal and tumor cell types were infected with NDV Ulster or NDV La Sota and viral $\mathrm{M}$ gene expression determined by qRT-PCR one day after infection. The numbers indicate the following cells: 1, spleen cells; 2, macrophages (BALB/c); 3, macrophages (DBA/2); 4, mature dendritic cells (BALB/c); 5, macrophages (C57BL/6); 6, ESb 289 (T cell lymphoma); 7, B16-OVA (melanoma); 8, DA3 (breast carcinoma); 9, B16-F10; 10, MB-49; 11, CT26w (colon carcinoma); 12, 3LL (lung carcinoma); 13, RAW; 14, J774. (B) Bone marrow-generated macrophages and the macrophage-derived tumor cel lines J774 and RAW were infected with NDV Ulster. Viral gene expression at the cell surface was measured by flow cytometry at different time-points after infection by staining with a polyclonal rabbit anti-NDV serum. (C) The same cells as in B were analyzed for the viral M gene expressionby qRT-PCR. For all the graphs of this figure, the results are represented as the mean of three measurements. Bars indicate standard deviation for $\mathrm{A}$ and $\mathrm{C}$.

positive for viral proteins at the cell surface compared to only $4 \%$ of the macrophages. The J774 cells exhibited intermediate level of viral gene expression compared to the former two cell types with $55 \%$ of the cells positive for viral proteins at the cell surface and with an $\mathrm{M}$ gene expression about 9 times higher than in the normal macrophages. The relatively low $\mathrm{M}$ gene expression after NDV infection in the J774 tumor cells, when compared to the RAW cells and to most other tumor cell types, made these cells an interesting target for further analyses.

Correlation between antiviral gene expression and resistance to NDV infection. Next, we analysed the expression of IFN-related genes that are known to be involved in antiviral responses. These genes included cytosolic viral RNA receptors (RIG-I and MDA5), proteins involved in type I IFN signalling (IRF3, IRF7 and IFN-ß) and proteins with direct antiviral functions (PKR, OAS1a and Mx1). We compared the expression of these genes in the presence or absence of NDV infection (Fig. 2). The basal and NDV-induced expression of most genes was highest in primary macrophages. The NDV-induced gene expression in macrophages was set as $100 \%$ so that the expression in tumor cells could be compared. RAW cells displayed the lowest expression levels of the analysed genes, while their gene expression was intermediate in the $\mathrm{J} 774$ cells.

We observed that most genes were strongly induced by NDV infection. The expression of the two viral RNA helicase receptors RIG-I and MDA5, which are responsible for the initiation of an IFN response, was clearly highest in the primary macrophages. The RNA helicase LGP2, which has been suggested as a negative regulator of RIG-I and MDA5 (27), was also more strongly expressed in primary macrophages than in the two tumor cell lines (data not shown). The highest induction of gene expression in primary macrophages was seen for IRF7, a key transcription factor for type I IFNs. In the J774 and RAW tumor cell lines, the expression and induction of IRF7 was much lower, indicating a decreased ability of these cells to mount an IFN response. The expression of IRF3 was also higher in the primary macrophages than in the macrophage-derived tumor cells. IRF3 is important for the transcription of early IFN subtypes which, in turn, induce IRF7 by activating the IFN- $\alpha / \beta$ receptor. A slight induction of IRF3 could be observed in the two tumor cell types, but not in the macrophages. Nevertheless, IRF3 expression was still highest in primary macrophages after NDV infection. The three antiviral genes PKR, OAS1a and Mx1 were all most strongly expressed in macrophages. The macrophage-derived tumor cells have acquired defects in the expression of many antiviral genes. This could explain the decreased ability of the macrophage-derived tumor cells to fight viral infection. It is noteworthy that these defects were more pronounced in the RAW than in the J774 cells, an observation in accordance with the observed higher susceptibility of the RAW cells to NDV infection than the J774 cells.

More rapid NDV-induced IFN secretion in normal compared to tumor cells. Antiviral gene expression after virus infection is usually induced by type I IFNs, which are secreted following detection of viral danger signals such as viral RNA and which act in an autocrine as well as paracrine fashion. Since type I IFNs can inhibit cell growth and promote apoptosis, it has 
= Basal expression $\square=\mathrm{NDV}$-induced expression

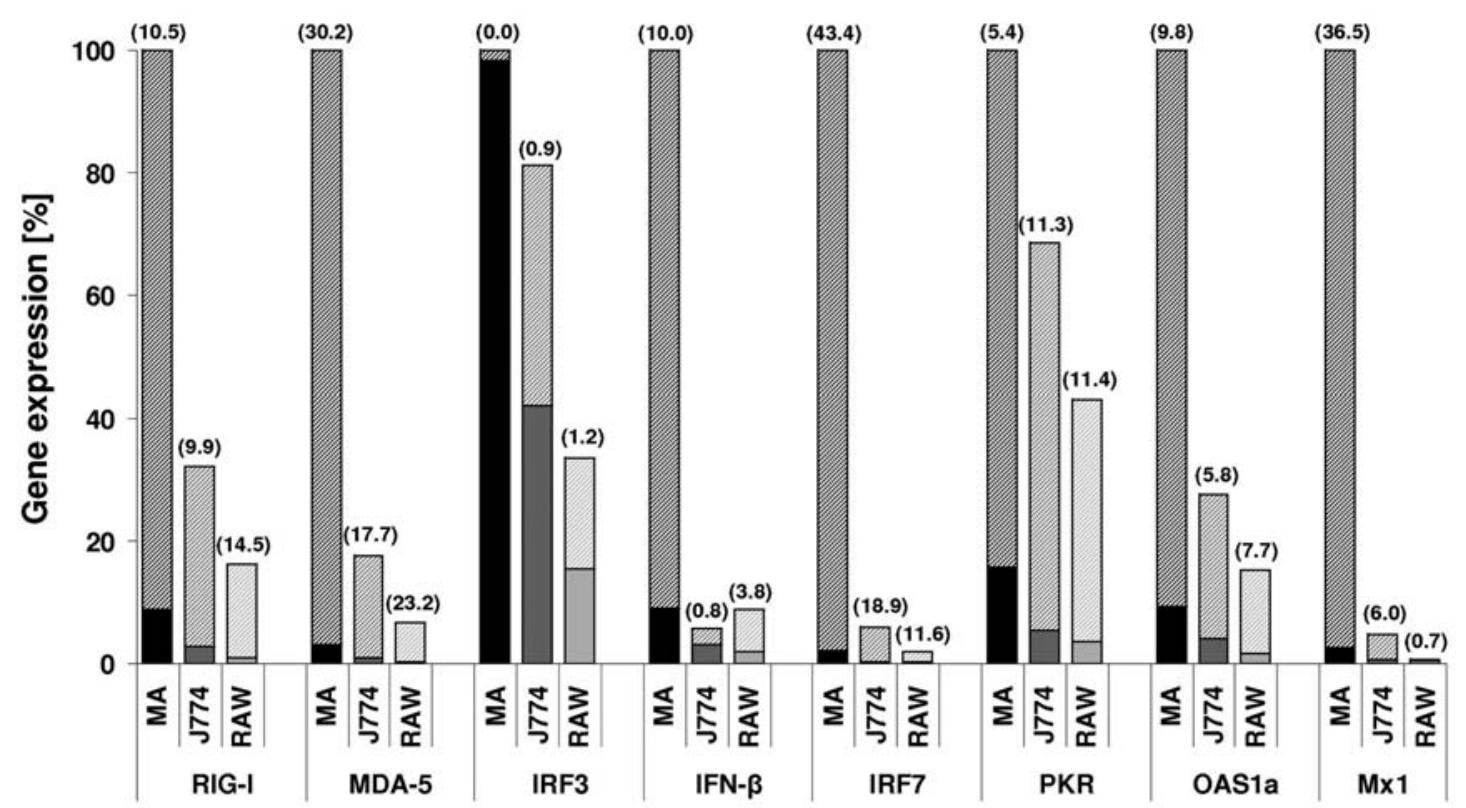

Interferon-related genes

Figure 2. Basal and NDV-induced expression of IFN-related genes in macrophages and macrophage-derived tumor cells. The expression of several IFNrelated genes was determined without or 1 day after NDV Ulster infection in macrophages, J774 and RAW cells with qRT-PCR. The genes were cytosolic receptors for viral RNA (RIG-I, retinoic acid-inducible gene I; MDA5, melanoma differentiation-associated gene 5), interferon regulatory factors (IRF3, IRF7), IFN-ß or antiviral effector molecules (PKR, protein kinase PKR; OAS1a, 2'-5'-oligoadenylate synthetase 1A; Mx1, myxovirus resistance 1). Gene expression is depicted relative to the expression in primary macrophages $12 \mathrm{~h}$ after NDV infection. The filled part of the bars indicates basal gene expression while the ruled part identifies the induction of gene expression after NDV infection. The numbers in brackets above the columns indicate the ratio of the NDV-induced versus the basal gene expression. MA, primary macrophages; J774, J774 tumor cells; RAW, RAW tumor cells.

been suggested that tumor cells often acquire defects in their IFN response giving them a growth and survival advantage (28). To ascertain differences between macrophages and macrophage-derived tumor cells in their ability to generate type I IFNs, we infected the cells with NDV Ulster and determined the amount of type I IFNs in the supernatant at different time-points after the addition of the virus.

As can be seen in Fig. 3A-C, macrophages secreted type I IFNs earlier than the two macrophage-derived tumor cell lines. IFN secretion started already 2-4 h after virus infection in the normal macrophages, while in the tumor cells it took 8-12 h before type I IFNs could be detected. The final amount of IFN- $\alpha$ detected by ELISA one day after infection was similar in normal macrophages and in the J774 cells. But this was about 20 times higher than in the RAW cells (Fig. 3A). The final amount of secreted IFN- $\beta$ protein as well as the total bioactive type I IFN was higher in the J774 cells than in the normal macrophages (Fig. 3B and C). The RAW cells exhibited only a low secretion of IFN- $\beta$ and bioactive type I IFN. These data suggest that the ability to secrete IFN rapidly after virus infection is important for their NDV resistance in general.

We also studied the kinetics of RIG-I induction to find out whether its expression preceeds IFN production. The results obtained in macrophages (Fig. 3D) show that this is the case, at least in normal macrophages derived from wildtype mice. Macrophages from type I IFN receptor (IFNAR) knock-out mice could also generate a RIG-I response, but this was slower and lower. The difference between the two curves observed in the Fig. 3D could be attributed to the interferon feedback loop.

Higher IFN-a responsiveness of normal compared to tumor cells. Another important factor for NDV resistance of cells could be also their responsiveness to type I IFNs via the IFN- $\alpha / \beta$ receptor (IFNAR). To address this point, we pretreated the primary macrophages and the two tumor cell lines with IFN- $\alpha 4$. This IFN- $\alpha$ subtype is usually secreted early after virus infection. We tested the induction of the antiviral genes RIG-I, IRF3, IRF7 and IFN- $\beta$ after such an IFN- $\alpha$ pretreatment.

Except for IRF3, the expression of the selected genes was increased in macrophages (Fig. 4A). In the two tumor cell lines, there was a slight increase in expression of RIG-I and IRF7, but this was always less than $20 \%$ in comparison to normal macrophages. The results thus demonstrate that the two macrophage-derived tumor cell lines are defective in their responsiveness to IFN- $\alpha$.

Next, we tested the induction of virus resistance via IFN- $\alpha 4$ pretreatment. Viral replication in the cells was evaluated by 
A
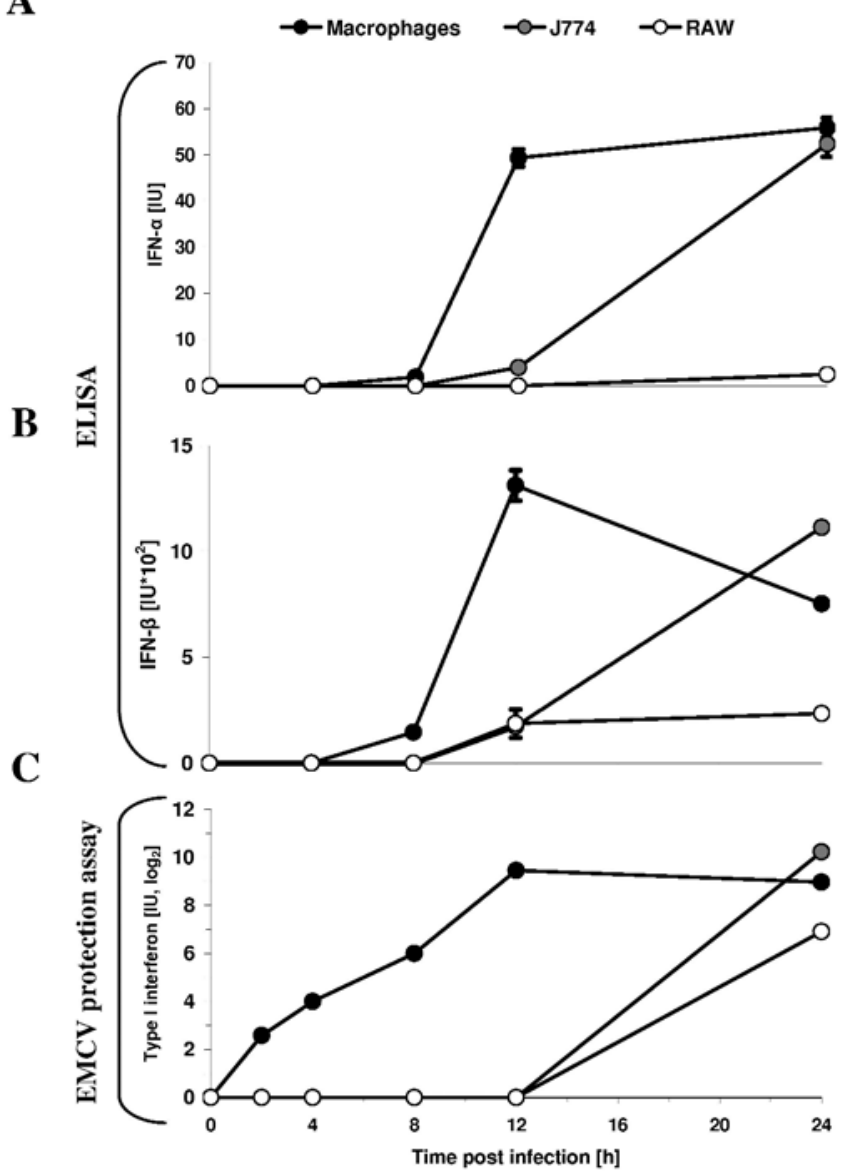

D

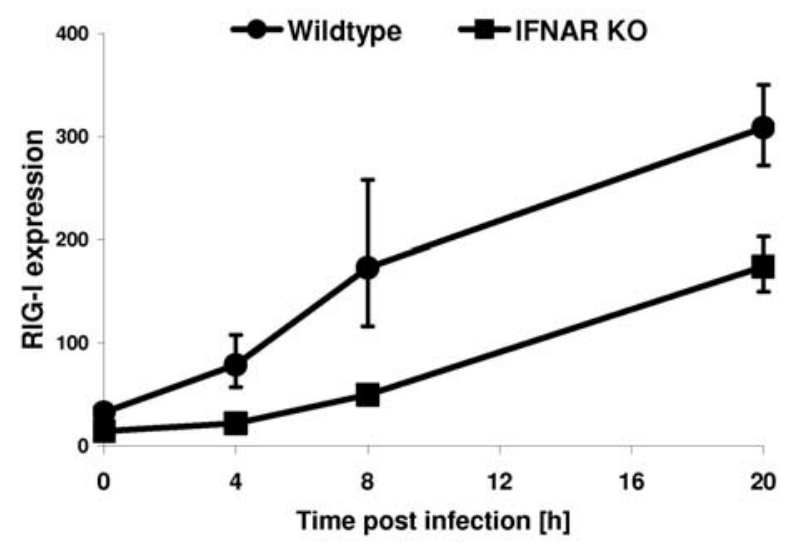

Figure 3. IFN secretion during NDV infection in macrophages and macrophage-derived tumor cells. Macrophages $\left(2 \times 10^{6}\right), \mathrm{J} 774$ or RAW cells were infected with NDV Ulster and seeded in $2 \mathrm{ml}$ growth medium. Type I IFNs were assessed in the supernatants at different time-points after infection. (A and B) The amount of IFN- $\alpha$ and $-\beta$ protein was measured with ELISA and (C) the biological activity of type I IFNs in the supernatants was assessed with an EMCV protection assay. (D) Wild-type and IFNAR knock-out macrophages were infected with NDV Ulster and RIG-I gene expression was determined by quantitative RT-PCR at different time-points after infection. The results are represented as the mean of three measurements. Bars indicate standard deviation.

determining the expression of the viral $\mathrm{M}$ gene generated by wild-type (wt) NDV Ulster or by the EGFP signal obtained after infection by the recombinant (rec) EGFP-expressing
$\mathbf{A}$

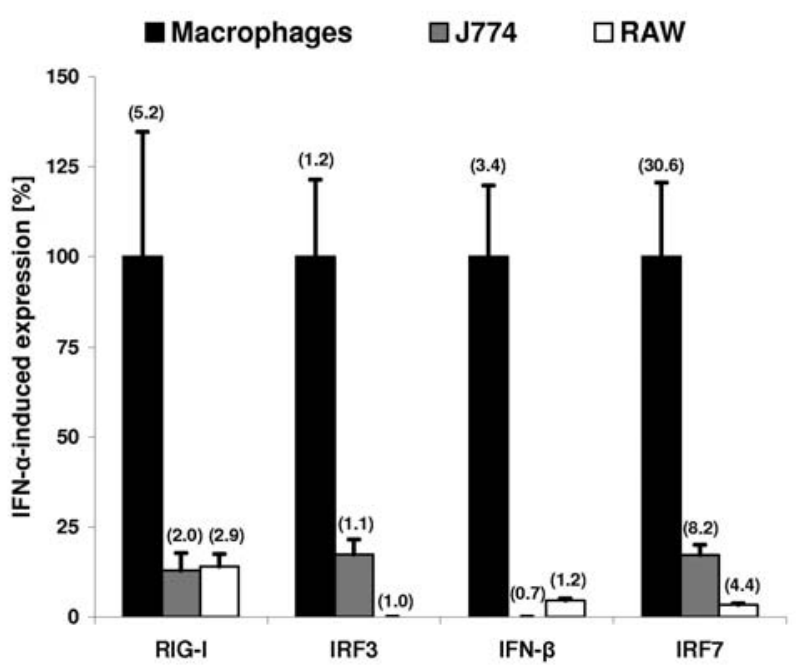

B

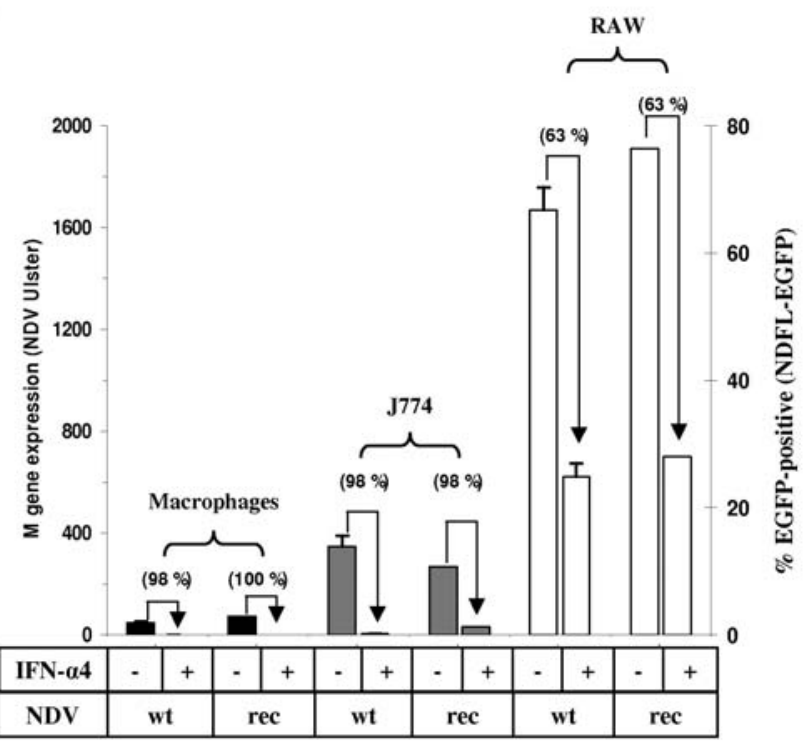

Figure 4. Influence of IFN- $\alpha$ pretreatment on antiviral gene expression and NDV infection in macrophages and macrophage-derived tumor cells. Macrophages, J774 and RAW cells were grown for 7 days either in normal medium or for 1 week in medium supplemented with $1500 \mathrm{U} / \mathrm{ml}$ anti-IFN- $\alpha$ and $1900 \mathrm{U} / \mathrm{ml}$ anti-IFN- $\beta$ antibody. The cells that were cultivated in antibody-supplemented medium were then grown for $16 \mathrm{~h}$ in medium

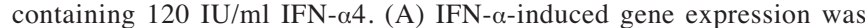
determined by qRT-PCR for RIG-I, IRF3, IRF7 and IFN-B. The numbers in brackets above the columns indicate the induction of gene expression as the ratio of the expression with to without IFN- $\alpha$ pretreatment. Results are represented as the mean of three measurements. Bars indicate standard deviation. (B) Cells with or without anti-IFN- $\alpha / B+I F N-\alpha 4$ pretreatment were infected with NDV Ulster and viral M gene expression was determined by qRT-PCR. The results are represented as the mean of three measurements. Bars indicate standard deviation. Alternatively, cells were infected with recombinant NDV La Sota expressing EGFP (NDFL-EGFP) and EGFP expression was measured with flow cytometry. The percentages in brackets above the columns indicate the blocking of the M or EGFP signal induced by the IFN- $\alpha$ pretreatment compared to the untreated cells. wt, wild-type NDV (Ulster); rec, NDFL-EGFP.

NDV La Sota (NDFL-EGFP). Fig. 4B shows that IFN- $\alpha$ pretreatment blocked viral $\mathrm{M}$ gene expression in all cells. Blocking was almost complete in primary macrophages and in the J774 cells. In the RAW cells, viral gene expression 
$\mathbf{A}$
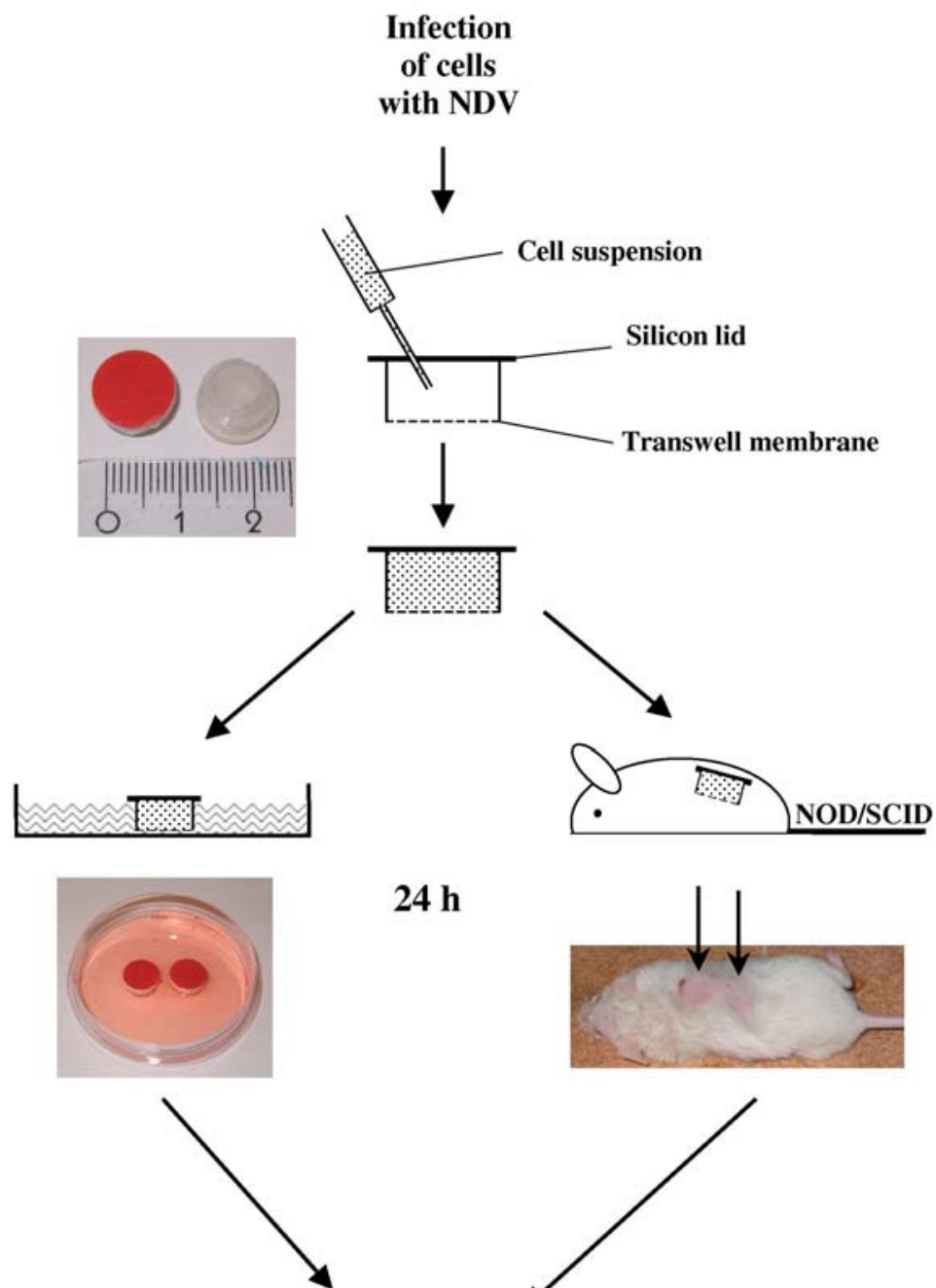

$24 \mathrm{~h}$
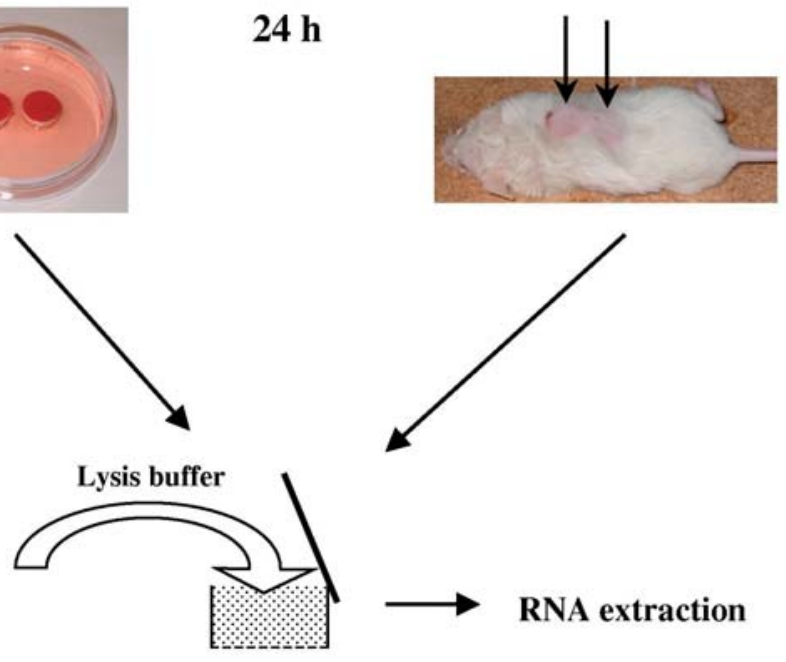

$\mathbf{B}$

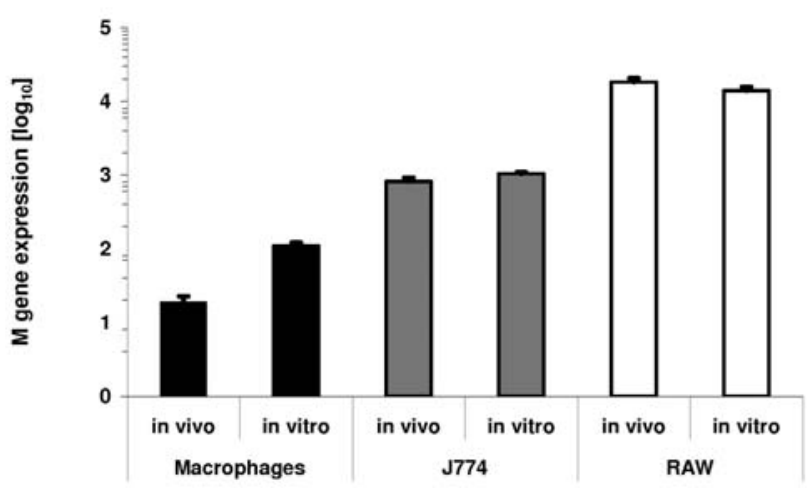

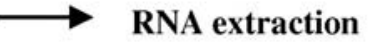

C

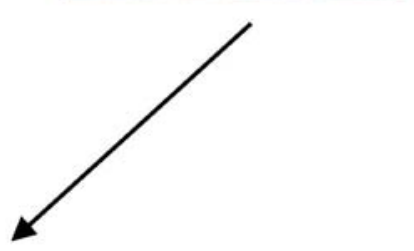

$\longrightarrow$ RNA extraction

$\square=$ Basal expression $\square=$ NDV-induced expression

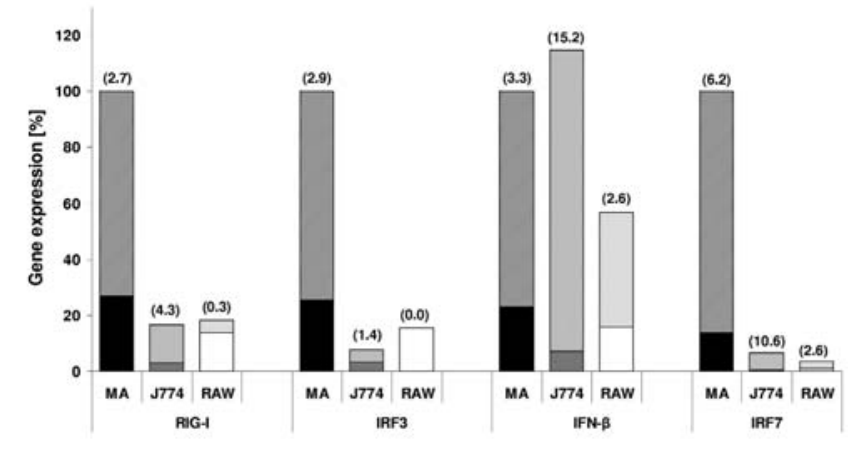

Figure 5. Chamber cultures: stimulation of interferon-related genes in vivo after NDV infection. (A) Schematic representation of the in vivo chamber experiments. NDV Ulster-infected or uninfected macrophages $\left(5 \times 10^{5}\right)$, J774 or RAW cells were injected with a syringe into the lumen of the chamber. Then the chambers were either kept in a plate with growth medium in a cell culture incubator (in vitro) or were implanted subcutaneously into the flank of NOD/SCID mice (in vivo). (B) After one day, total RNA was extracted and viral M gene expression determined by qRT-PCR. The results are represented as the mean of three measurements. Bars indicate standard deviation. (C) One day after infection, total RNA was extracted and IFN-related gene expression determined by qRT-PCR in cells grown in chambers in vivo. Gene expression is depicted relative to the primary macrophages. The filled parts of the bars indicate basal gene expression while the ruled part identifies the induction of gene expression after NDV infection. The numbers in brackets above the columns indicate the ratio of the NDV-induced versus the basal gene expression. 
was still at $37 \%$ of the level without IFN- $\alpha$ pretreatment. Hence, the RAW cells were defective in their ability to generate an antiviral state in response to IFN- $\alpha$ when compared to primary macrophages.

Differences in viral and antiviral gene expression in vivo after NDV infection in normal and tumor cells. Having seen the various differences between normal and tumor cells in their response to infection by NDV in vitro, it was important to exclude that these findings are in vitro artefacts and to confirm their relevance under in vivo growth conditions in live animals. To verify this, we used a sophisticated microchamber system which we established before to study tumor endothelium-mediated regulatory $\mathrm{T}$ cell infiltration of human pancreatic carcinoma (26). Fig. 5A shows a scheme of the experimental procedure. The chambers were loaded with infected or non-infected test cells. They were then implanted subcutaneously into immune incompetent NOD/SCID mice. In parallel, some chambers were kept in culture medium and were used as an in vitro control.

A Transwell membrane with $3 \mu \mathrm{m}$ pore size connected the lumen of the chamber to the peritoneum of the mouse and its fluid. These chambers allowed to recover the cells from the mice, excluding any contamination by surrounding murine tissue for the ensuing analyses.

Viral M gene expression inside the chambers by the three cell types measured one day after infection with NDV Ulster reflected the differences seen during the in vitro studies (Fig. 5B). The macrophages showed the lowest and the RAW cells the highest M gene expression. The J774 cells were intermediate in this respect. The macrophages had a 10-fold higher $\mathrm{M}$ gene expression when cultured inside the chamber kept in vitro in comparison to the chamber implanted in vivo. In general, $\mathrm{M}$ gene expression in the chambers was higher for all three cell types when tested in vivo and in vitro as compared to the results obtained previously in cell culture.

The expression of IFN-related genes in the three cell types inside the chambers (Fig. 5C) was similar to the in vitro results obtained without chambers (Fig. 2). In most cases gene expression was higher in macrophages than in the two macrophage-derived tumor cell lines. An exception was the expression of IFN- $\beta$ which was strongest in the J774 tumor cells. One difference to the cells grown in cell culture in vitro (Fig. 2) is that NDV could further upregulate IRF3 levels in vivo (Fig. $5 \mathrm{C}$ ). Most importantly, the results show that the differences between primary macrophages and macrophagederived tumor cells, which have been observed in vitro, can be seen also in vivo.

Inverse correlation between antiviral gene expression and NDV susceptibilty in different normal and tumor cell types. So far the results suggest that defects at the basal or inducible expression of IFN-related genes correlate with an increased susceptibility of macrophage-derived tumor cells to infection by NDV. In order to find out if such defects are a common feature of tumor cells in general, a panel of tumor and normal cells of different origins were tested. These cells were infected with NDV and viral gene expression was correlated with the basal and NDV-induced expression level of the IFN-related genes RIG-I, IRF3, IRF7 and IFN-B.

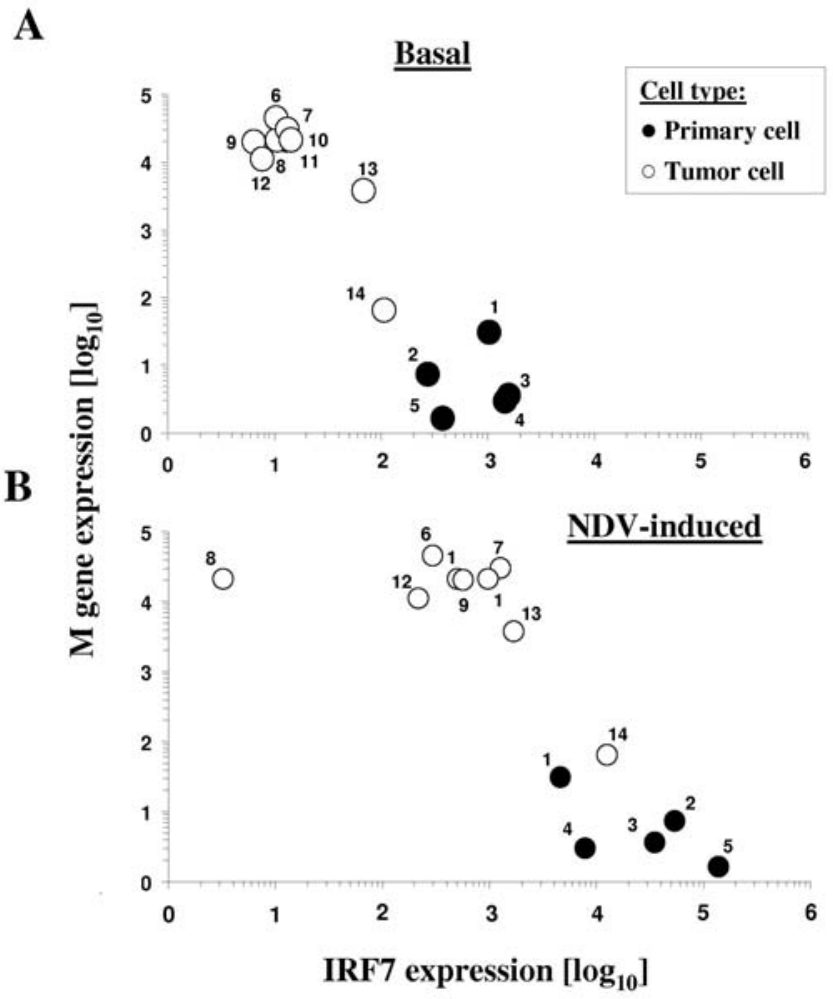

Figure 6. Correlation between IRF7 expression and NDV susceptibility. Total RNA from different non-malignant or tumor cell types was extracted from cells without or 1 day after NDV infection and IRF7 as well as NDV M gene expression was determined by qRT-PCR. The basal (A) or NDV-induced IRF7 expression (B) was plotted against the NDV M gene level $24 \mathrm{~h}$ after infection. Tumor cell types are depicted as dark circles $(\bullet)$ and normal cell types are represented by light circles $(0)$. The numbers indicate the cell type as in the legend of Fig. 1A. The results are represented as the mean of three measurements.

For the basal and NDV-induced IRF7 expression, an inverse correlation was found with the $\mathrm{M}$ gene expression (Fig. 6). In this figure, two cell clusters can be distinguished. One cluster (corresponding to the white symbols) is made up mostly of tumor cells. These cells show a low IRF7 and a high viral gene expression. The other cluster (with black symbols) is made up mostly of macrophages and other non-malignant cell types. These cells display a high IRF7 and a low viral gene expression after NDV infection. A similar distribution of tumor and normal cells was found in a correlation analysis for the basal and NDV-induced expression of RIG-I, IRF3 and IFN-B (data not shown). When the expression data were analysed further (Table I), it was demonstrated that the basal and NDV-induced expression of the four genes was significantly lower in tumor than in normal cells, with the only exception of the induced expression of IFN-B (Table I, 3rd column). When the Spearman's correlation coefficient $r_{S}$ was calculated, there was always a strong and significant inverse correlation between the viral $\mathrm{M}$ gene expression and the basal expression of the four genes (Table I, 4th column). The correlation was weaker and not significant for the $\mathrm{M}$ gene expression and NDV-induced expression of the four genes except for IRF7. These data strongly suggest that a low expression of antiviral genes is a common feature of tumor cells and is associated with their 
Table I. IFN-related gene expression and correlation with NDV susceptibility.

\begin{tabular}{|c|c|c|c|}
\hline Gene & Expression & $\begin{array}{c}\text { Gene expression tumor versus } \\
\text { normal cell types }\end{array}$ & $\begin{array}{l}\text { Correlation } \mathrm{r}_{\mathrm{S}} \text { of antiviral and } \\
\text { NDV M gene expression }\end{array}$ \\
\hline \multirow[t]{4}{*}{ RIG-I } & Basal & $\downarrow^{\mathrm{b}}$ & $-0.76^{b}$ \\
\hline & & & CI: -0.93 to -0.35 \\
\hline & NDV-induced & $\downarrow^{\mathrm{a}}$ & $-0.50^{c}$ \\
\hline & & & CI: -0.83 to 0.09 \\
\hline \multirow[t]{4}{*}{ IRF3 } & Basal & $\downarrow^{\mathrm{b}}$ & $-0.69^{b}$ \\
\hline & & & CI: -0.90 to -0.20 \\
\hline & NDV-induced & $\downarrow^{\mathrm{a}}$ & $-0.43^{c}$ \\
\hline & & & CI: -0.80 to 0.18 \\
\hline \multirow[t]{4}{*}{ IFN-B } & Basal & ns & $-0.83^{b}$ \\
\hline & & & CI: -0.95 to -0.54 \\
\hline & NDV-induced & ns & $0.19^{c}$ \\
\hline & & & CI: -0.39 to 0.67 \\
\hline \multirow[t]{4}{*}{ IRF7 } & Basal & $\downarrow^{\mathrm{b}}$ & $-0.79^{b}$ \\
\hline & & & CI: -0.93 to -0.43 \\
\hline & NDV-induced & $\downarrow^{\mathrm{a}}$ & $-0.82^{\mathrm{b}}$ \\
\hline & & & CI: -0.94 to -0.49 \\
\hline
\end{tabular}

Basal and NDV-induced expression of RIG-I, IRF3, IRF7 and IFN- 3 was analysed in different normal and tumor cell types by qRT-PCR. Arrows $(\downarrow)$ in the middle column indicate a lower expression of the respective gene in tumor than in normal cell types. The analysed cell types are the ones listed in Fig. 6. In addition, basal gene expression of normal murine lung and liver tissue was included. P-values were calculated using the Student's t-test. In the right column, the correlation between the basal and NDV-induced expression of the four genes and viral $\mathrm{M}$ gene expression $24 \mathrm{~h}$ after infection was assessed by calculating the Spearman's correlation coefficient $\mathrm{r}_{\mathrm{S}}$ and the corresponding p-value. CI, 95\% confidence interval; ${ }^{\mathrm{a}} \mathrm{p}<0.05 ;{ }^{\mathrm{b}} \mathrm{p}<0.01 ;{ }^{\mathrm{c}} \mathrm{ns}$, not significant.

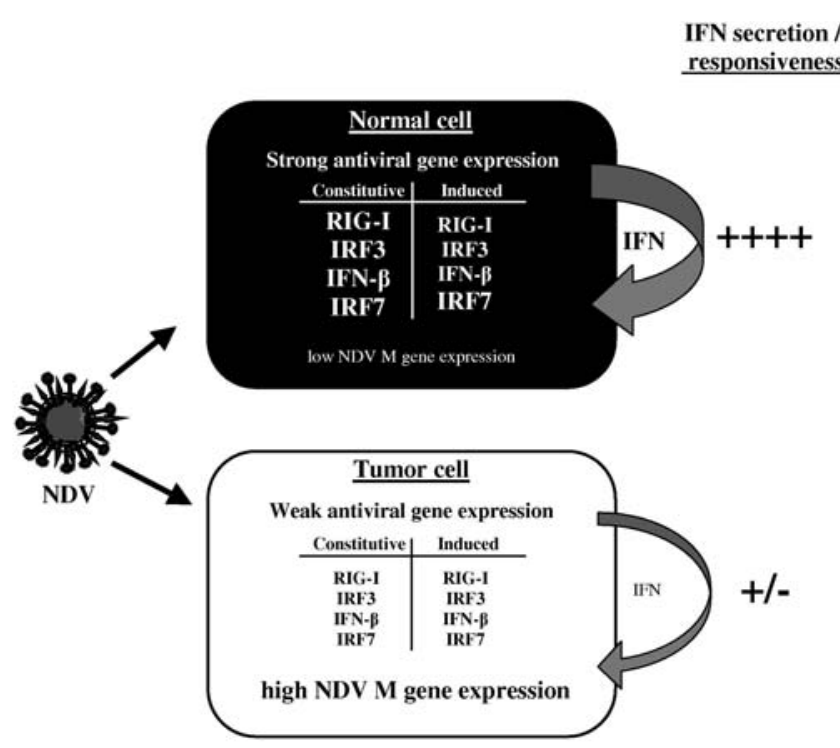

Figure 7. Model for the molecular basis of NDV tumor selectivity. The model takes into consideration the observations that normal cells display a higher constitutive and also NDV-induced expression of antiviral genes such as RIG-I, IRF3, IRF7 or IFN- $\beta$ compared to tumor cells. Moreover, normal cells are predicted to exhibit a faster and stronger secretion of type I IFNs than tumor cells. The model also shows that tumor cells are defective in their responsiveness to type I IFN. The defects at different stages of the antiviral IFN response makes tumor cells much more susceptible to NDV infection than normal cells. The size of the characters used for the antiviral proteins refects their expression level. high susceptibility to infection by NDV in contrast to normal cells.

\section{Discussion}

The tumor selective replication of NDV is the cornerstone for its clinical application and good tolerability in cancer patients. Many tumor cells have a defect in their ability to mount a type I IFN response upon infection with different viruses. This has been demonstrated in particular for RNA viruses such as NDV (29,30), VSV (31-33) and influenza virus (34). Nevertheless, the molecular nature of the defects in the IFN pathway has not yet been clearly defined. Here we elucidate for the first time four genes that could be important to explain the different behaviour of tumor cells versus non-malignant cells upon infection by NDV. The basal and NDV-induced expression of antiviral IFN-related genes was clearly lower in tumor cells than in non-malignant cells. Furthermore, the macrophage-derived tumor cells displayed a delayed secretion of type I IFNs and a decreased responsiveness to IFN- $\alpha$. Gene expression analysis of the antiviral genes RIG-I, IRF3, IRF7 and IFN- $\beta$ revealed their significant downregulation in tumor cells. There was a strong and statistically significant negative correlation between the expression of these genes and the susceptibility to NDV infection. We can therefore conclude that differences in 
the expression of distinct antiviral IFN-related genes is associated with the resistance of normal cells and the susceptibility of tumor cells to NDV infection.

Is this conclusion justified and how general is it? We compared normal and tumor cells of the same histological origin to exclude that differences observed in the IFN response could be attributed to differences in the cell type. For gene expression analysis, we selected genes which are representative for important IFN pathways. The four genes that were extensively analysed were RIG-I, IRF3, IRF7 and IFN- $\beta$. The cytosolic receptors RIG-I and MDA5 are essential for the recognition of viral RNA in the cytosol $(16,27)$. RIG-I is necessary for an early antiviral response (35) and is more important for the detection of paramyxoviruses than MDA5 (15). IRF3 and IRF7 are indispensible for the induction of type I IFNs (36).

The basal expression of these four genes correlated inversely with NDV susceptibility when a panel of normal and tumor cell types was tested. Such strong, statistically significant correlation could not be found for the NDV-induced changes in the expression of these genes except IRF7. This suggests that, for NDV resistance, the amount of gene product at the time of virus infection is more important than the amount generated after infection. In tumor cells showing a low constitutive expression of antiviral proteins, virus replication might progress too far to be significantly inhibited by these proteins. Later on during the infection, the induced antiviral proteins cannot block anymore the virus that has already invaded the cells. Only the induction of IRF7 after virus infection appears to be able to inhibit virus replication, underlining the central importance of this molecule for antiviral responses. IRF7 has been found to be the master regulator of the control of type I IFN-dependent immune responses (37).

It is not yet clear which mechanisms lead to the downregulation of IFN-related genes in tumor cells. It is possible that IRF3 plays an important role. Unlike most of the other tested genes, IRF3 is thought to be constitutively expressed in normal cells (38). Following NDV infection or interferon treatment, only a very small upregulation of IRF3 expression was observed. This protein is important for the early secretion of IFN- $\beta$ and some IFN- $\alpha$ subtypes after virus infection. Many viruses target IRF3 signalling to limit the induction of antiviral responses (39-41). Since most other genes tested in this study were induced by IFNs in tumor cells, we suggest that the decreased constitutive expression of IRF3 in tumor cells is a main determinant for their limited expression of antiviral genes.

A defective expression of IRF3 is likely responsible for the delay of type I IFN secretion in macrophage-derived tumor cells after NDV infection. The IFN response of macrophages is characterized by a rapid onset and a rapid decline of IFN production. Such a kinetic limits the release of IFN to a short time interval (42). The delayed IFN secretion of the tumor cells correlated with their higher susceptibility to NDV infection. The final type I IFN level in the J774 cells was even higher than in the primary macrophages. The kinetics may thus be more important than the level of interferon produced. Basal antiviral gene expression depends on constitutively secreted type I IFNs, which have been shown to be produced also in the absence of virus infection (43). This can also explain the observed reduced RIG-I response in IFNAR knock-out macrophages. The high basal expression of IRF3 in wild-type macrophages could limit virus replication early on and lead to a fast interferon response.

Another reason for the lower antiviral gene expression in tumor cells could be the decreased responsiveness to IFNs as observed for the macrophage-derived tumor cells. A low expression of the IFNAR as well as of other IFN-stimulated genes has been suggested as a cause for the low IFN responsiveness of tumor cells $(44,45)$. In melanoma cells, defects in the IFNAR Jak-STAT pathway were thought to have led to cancer progression through loss of growth-restraining functions of IFN (46). In addition an activated RAS/Raf1/ MEK/ERK pathway has been described to be involved in decreased IFN responsiveness of tumor cells (47).

RIG-I, the expression of which is regulated by the tumor suppressor IRF1, has itself been suggested to posess tumor suppressor properties (48). IRF1 is also induced by type I IFNs and is expressed at a higher level in normal than in tumor cells (48). The expression of the antiviral effector molecules PKR, OAS1a and Mx1 also correlated with the susceptibility to NDV infection of primary macrophages and macrophage-derived tumor cells. These molecules inhibit critical steps of viral replication such as RNA translation or assembly of virus particles. Antiviral effector molecules might be downregulated in tumor cells because they can induce apoptosis, as is known for PKR (49) or OAS1a (50).

The high susceptibility to infection by NDV and the low expression of IFN-related genes of the two macrophagederived tumor cells in vitro could be confirmed for an in vivo situation with implantable micro-chambers. In these chambers, which have been applied in live mice, the in situ expression of IFN-related genes was highest in primary macrophages, intermediate in the J774 and lowest in the RAW cells. In general, basal antiviral gene expression in the three cell types was higher in vivo than in vitro. This might be attributable to a higher level of expression in vivo due to the presence of plasmacytoid dendritic cells, the principal type I IFN producing cell type (51). The NDV-induced expression of IFN- 3 was also higher in vivo than in vitro. This finding might also be due to the higher constitutive expression levels of IFN in vivo that increase the responsiveness to virus infection. It is important to note that similar differences with regard to NDV susceptibility were observed in vivo as in vitro between tumor cells and normal cells.

Based on the results obtained in this study, we propose a model for the molecular basis of the tumor selectivity of NDV replication (Fig. 7). In this model, the identified four antiviral genes could play an important role. Tumor selectivity of replication seems to be due to a weak constitutive and NDV-induced expression of these four antiviral genes, to a low interferon secretion and to a reduced responsiveness to type I interferons in tumor as compared to normal cells. The extent of these defects, especially in the constitutive antiviral gene expression, determines the susceptibility to NDV infection.

In the future, expression profiling for these genes could be used to determine the suitability of NDV for oncolytic cancer virotherapy in a patient by assessing antiviral gene 
expression in its tumor tissue. Safety and efficacy studies have already been performed with NDV in clinical studies with different types of cancer $(1,3,4,6)$. Other oncolytic viruses such as vaccinia virus $(52,53)$ and $\operatorname{HSV}(54,55)$ are also being evaluated in clinical studies. In China a genetically modified oncolytic adenovirus has already been approved as a new biological drug for cancer treatment (56). If in future oncolytic NDV is given only to cancer patients whose tumor shows a low expression profile for RIG-I, IRF3, IRF7 and IFN- $\beta$, this might increase the clinical efficiency of this new virotherapeutic agent.

\section{Acknowledgements}

We thank Dr Ben Peeters from the Division of Infectious Diseases, Animal Sciences Group, Wageningen UR, AB Lelystad (The Netherlands) for the recombinant EGFPexpressing NDV. We also acknowledge the help of Axel Benner from the Department of Biostatistics of the German Cancer Research Center (Heidelberg, Germany) with the statistical analyses. We are grateful to Tobias Seibel for his assistance with the micro-chamber system.

\section{References}

1. Lorence RM, Roberts MS, O'Neil JD, et al: Phase 1 clinical experience using intravenous administration of PV701, an oncolytic Newcastle disease virus. Curr Cancer Drug Targets 7: 157-167, 2007

2. Csatary LK, Gosztonyi G, Szeberenyi J, et al: MTH-68/H oncolytic viral treatment in human high-grade gliomas. J Neurooncol 67: 83-93, 2004.

3. Freeman AI, Zakay-Rones Z, Gomori JM, et al: Phase I/II trial of intravenous NDV-HUJ oncolytic virus in recurrent glioblastoma multiforme. Mol Ther 13: 221-228, 2006.

4. Hotte SJ, Lorence RM, Hirte HW, et al: An optimized clinical regimen for the oncolytic virus PV701. Clin Cancer Res 13: 977-985, 2007

5. Laurie SA, Bell JC, Atkins HL, et al: A phase 1 clinical study of intravenous administration of PV701, an oncolytic virus, using two-step desensitization. Clin Cancer Res 12: 2555-2562, 2006.

6. Pecora AL, Rizvi N, Cohen GI, et al: Phase I trial of intravenous administration of PV701, an oncolytic virus, in patients with advanced solid cancers. J Clin Oncol 20: 2251-2266, 2002.

7. Schirrmacher V: Clinical trials of antitumor vaccination with an autologous tumor cell vaccine modified by virus infection: improvement of patient survival based on improved antitumor immune memory. Cancer Immunol Immunother 54: 587-598, 2005.

8. Schlag P, Manasterski M, Gerneth T, et al: Active specific immunotherapy with Newcastle-disease-virus-modified autologous tumor cells following resection of liver metastases in colorectal cancer. First evaluation of clinical response of a phase II-trial. Cancer Immunol Immunother 35: 325-330, 1992.

9. Steiner HH, Bonsanto MM, Beckhove $\mathrm{P}$, et al: Antitumor vaccination of patients with glioblastoma multiforme: a pilot study to assess feasibility, safety, and clinical benefit. J Clin Oncol 22: 4272-4281, 2004

10. Schulze T, Weitz J, Kemmer W, Wernecke KD, Schirrmacher V and Schlag PM: Efficiency of adjuvant active specific immunization with Newcastle Disease Virus modified tumor cells in colorectal cancer patients following resection of liver metastases - results of a prospective randomized trial. Cancer Immunol Immunother (In press).

11. Reichard KW, Lorence RM, Cascino CJ, et al: Newcastle disease virus selectively kills human tumor cells. J Surg Res 52: 448-453, 1992

12. Guha-Thakurta N and Majde JA: Early induction of proinflammatory cytokine and type I interferon mRNAs following Newcastle disease virus, poly [rI:rC], or low-dose LPS challenge of the mouse. J Interferon Cytokine Res 17: 197-204, 1997.
13. Washburn B and Schirrmacher V: Human tumor cell infection by Newcastle Disease Virus leads to upregulation of HLA and cell adhesion molecules and to induction of interferons, chemokines and finally apoptosis. Int J Oncol 21: 85-93, 2002.

14. Park MS, Garcia-Sastre A, Cros JF, Basler CF and Palese P: Newcastle disease virus $\mathrm{V}$ protein is a determinant of host range restriction. J Virol 77: 9522-9532, 2003.

15. Kato H, Takeuchi O, Sato S, et al: Differential roles of MDA5 and RIG-I helicases in the recognition of RNA viruses. Nature 441: 101-105, 2006.

16. Yoneyama M, Kikuchi M, Natsukawa T, et al: The RNA helicase RIG-I has an essential function in double-stranded RNA-induced innate antiviral responses. Nat Immunol 5: 730-737, 2004

17. Hornung V, Ellegast J, Kim S, et al: 5'-Triphosphate RNA is the ligand for RIG-I. Science 314: 994-997, 2006.

18. Pichlmair A, Schulz O, Tan CP, et al: RIG-I-mediated antiviral responses to single-stranded RNA bearing 5'-phosphates. Science 314: 997-1001, 2006

19. Mogensen KE, Lewerenz M, Reboul J, Lutfalla G and Uze G: The type I interferon receptor: structure, function, and evolution of a family business. J Interferon Cytokine Res 19: 1069-1098, 1999.

20. Prakash A, Smith E, Lee CK and Levy DE: Tissue-specific positive feedback requirements for production of type I interferon following virus infection. J Biol Chem 280: 18651-18657, 2005.

21. Sato M, Hata N, Asagiri M, Nakaya T, Taniguchi T and Tanaka N: Positive feedback regulation of type I IFN genes by the IFN-inducible transcription factor IRF-7. FEBS Lett 441 : 106-110, 1998

22. Marie I, Durbin JE and Levy DE: Differential viral induction of distinct interferon-alpha genes by positive feedback through interferon regulatory factor-7. EMBO J 17: 6660-6669, 1998

23. Al-Garib SO, Gielkens AL, Gruys E, Peeters BP and Koch G: Tissue tropism in the chicken embryo of non-virulent and virulent Newcastle diseases strains that express green fluorescence protein. Avian Pathol 32: 591-596, 2003.

24. Schirrmacher V, Ahlert T, Probstle T, et al: Immunization with virus-modified tumor cells. Semin Oncol 25: 677-696, 1998.

25. Nickolaus P, Rammensee HG and Zawatzky R: Interferoninduced expression of If-1h and If-11 alleles in Newcastle disease virus-infected mouse macrophages is associated with specific differences in viral gene transcription. J Interferon Cytokine Res 18: 187-196, 1998.

26. Nummer D, Suri-Payer E, Schmitz-Winnenthal H, et al: Role of tumor endothelium in $\mathrm{CD}^{+} \mathrm{CD} 25^{+}$regulatory $\mathrm{T}$ cell infiltration of human pancreatic carcinoma. J Natl Cancer Inst 99: 1188-1199, 2007.

27. Yoneyama M, Kikuchi M, Matsumoto K, et al: Shared and unique functions of the DExD/H-box helicases RIG-I, MDA5, and LGP2 in antiviral innate immunity. J Immunol 175: 2851-2858, 2005.

28. Stojdl DF, Lichty B, Knowles S, et al: Exploiting tumor-specific defects in the interferon pathway with a previously unknown oncolytic virus. Nat Med 6: 821-825, 2000.

29. Fiola C, Peeters B, Fournier P, Arnold A, Bucur M and Schirrmacher V: Tumor selective replication of Newcastle disease virus: association with defects of tumor cells in antiviral defence. Int J Cancer 119: 328-338, 2006.

30. Krishnamurthy S, Takimoto T, Scroggs RA and Portner A: Differentially regulated interferon response determines the outcome of Newcastle disease virus infection in normal and tumor cell lines. J Virol 80: 5145-5155, 2006.

31. Obuchi M, Fernandez M and Barber GN: Development of recombinant vesicular stomatitis viruses that exploit defects in host defense to augment specific oncolytic activity. J Virol 77 : 8843-8856, 2003.

32. Stojdl DF, Lichty BD, tenOever BR, et al: VSV strains with defects in their ability to shutdown innate immunity are potent systemic anti-cancer agents. Cancer Cell 4: 263-275, 2003.

33. Wollmann G, Robek MD and van den Pol AN: Variable deficiencies in the interferon response enhance susceptibility to vesicular stomatitis virus oncolytic actions in glioblastoma cells but not in normal human glial cells. J Virol 81: 1479-1491, 2007.

34. Muster T, Rajtarova J, Sachet M, et al: Interferon resistance promotes oncolysis by influenza virus NS1-deletion mutants. Int J Cancer 110: 15-21, 2004. 
35. Liu P, Jamaluddin M, Li K, Garofalo RP, Casola A and Brasier AR: Retinoic acid-inducible gene I mediates early antiviral response and Toll-like receptor 3 expression in respiratory syncytial virus-infected airway epithelial cells. J Virol 81: 1401-1411, 2007.

36. Sato M, Suemori H, Hata N, et al: Distinct and essential roles of transcription factors IRF-3 and IRF-7 in response to viruses for IFN-alpha/beta gene induction. Immunity 13: 539-548, 2000.

37. Honda K, Yanai H, Negishi $\mathrm{H}$, et al: IRF-7 is the master regulator of type-I interferon-dependent immune responses. Nature 434: 772-777, 2005.

38. Au WC, Moore PA, Lowther W, Juang YT and Pitha PM: Identification of a member of the interferon regulatory factor family that binds to the interferon-stimulated response element and activates expression of interferon-induced genes. Proc Natl Acad Sci USA 92: 11657-11661, 1995.

39. Foy E, Li K, Wang C, et al: Regulation of interferon regulatory factor- 3 by the hepatitis $C$ virus serine protease. Science 300: 1145-1148, 2003.

40. Mibayashi M, Martinez-Sobrido L, Loo YM, Cardenas WB Gale M Jr and Garcia-Sastre A: Inhibition of retinoic acidinducible gene I-mediated induction of beta interferon by the NS1 protein of influenza A virus. J Virol 81: 514-524, 2007.

41. Poole E, He B, Lamb RA, Randall RE and Goodbourn S: The V proteins of simian virus 5 and other paramyxoviruses inhibit induction of interferon-beta. Virology 303: 33-46, 2002.

42. Hoss-Homfeld A, Zwarthoff EC and Zawatzky R: Cell type specific expression and regulation of murine interferon alpha and beta genes. Virology 173: 539-550, 1989.

43. Lallemand C, Lebon P, Rizza P, Blanchard B and Tovey MG: Constitutive expression of specific interferon isotypes in peripheral blood leukocytes from normal individuals and in promonocytic U937 cells. J Leukoc Biol 60: 137-146, 1996.

44. Holko M and Williams BR: Functional annotation of IFNalpha-stimulated gene expression profiles from sensitive and resistant renal cell carcinoma cell lines. J Interferon Cytokine Res 26: 534-547, 2006.

45. Wagner TC, Velichko S, Chesney SK, et al: Interferon receptor expression regulates the antiproliferative effects of interferons on cancer cells and solid tumors. Int J Cancer 111: 32-42, 2004.
46. Pansky A, Hildebrand P, Fasler-Kan E, et al: Defective Jak-STAT signal transduction pathway in melanoma cells resistant to growth inhibition by interferon-alpha. Int J Cancer 85: 720-725, 2000.

47. Noser JA, Mael AA, Sakuma R, et al: The RAS/Raf1/MEK/ ERK signaling pathway facilitates VSV-mediated oncolysis: implication for the defective interferon response in cancer cells. Mol Ther 15: 1531-1536, 2007.

48. Su ZZ, Sarkar D, Emdad L, Barral PM and Fisher PB: Central role of interferon regulatory factor-1 (IRF-1) in controlling retinoic acid inducible gene-I (RIG-I) expression. J Cell Physiol 213: 502-510, 2007.

49. Pataer A, Vorburger SA, Barber GN, et al: Adenoviral transfer of the melanoma differentiation-associated gene 7 (mda7) induces apoptosis of lung cancer cells via up-regulation of the double-stranded RNA-dependent protein kinase (PKR). Cancer Res 62: 2239-2243, 2002.

50. Bisbal C and Silverman RH: Diverse functions of RNase L and implications in pathology. Biochimie 89: 789-798, 2007.

51. Cella M, Jarrossay D, Facchetti F, et al: Plasmacytoid monocytes migrate to inflamed lymph nodes and produce large amounts of type I interferon. Nat Med 5: 919-923, 1999.

52. Eder JP, Kantoff PW, Roper K, et al: A phase I trial of a recombinant vaccinia virus expressing prostate-specific antigen in advanced prostate cancer. Clin Cancer Res 6: 1632-1638, 2000.

53. Marshall JL, Hoyer RJ, Toomey MA, et al: Phase I study in advanced cancer patients of a diversified prime-and-boost vaccination protocol using recombinant vaccinia virus and recombinant nonreplicating avipox virus to elicit anticarcinoembryonic antigen immune responses. J Clin Oncol 18: 3964-3973, 2000

54. Hu JC, Coffin RS, Davis CJ, et al: A phase I study of OncoVEXGM-CSF, a second-generation oncolytic herpes simplex virus expressing granulocyte macrophage colonystimulating factor. Clin Cancer Res 12: 6737-6747, 2006.

55. Kemeny N, Brown K, Covey A, et al: Phase I, open-label, doseescalating study of a genetically engineered herpes simplex virus, NV1020, in subjects with metastatic colorectal carcinoma to the liver. Hum Gene Ther 17: 1214-1224, 2006.

56. Garber K: China approves world's first oncolytic virus therapy for cancer treatment. J Natl Cancer Inst 98: 298-300, 2006. 